\title{
Potential Role of Hypothalamic and Plasma Ghrelin in the Feeding Behavior of Obese Type 2 Diabetic Rats with Intraventricular Glucagon-Like Peptide-1 Receptor Agonist Intervention
}

\author{
$\mathrm{Ke} \mathrm{Lu}^{\mathrm{a}}$ Xiaoyan Chen $^{\mathrm{a}}$ Xuelian Deng $^{\mathrm{a}}$ Juan Long ${ }^{\mathrm{a}}$ Jianhua Yan $^{\mathrm{b}}$ \\ ${ }^{a}$ Department of Endocrinology, First Affiliated Hospital of Guangzhou Medical University, Guangzhou, China; \\ bShanghai Key Laboratory for Molecular Imaging, Shanghai University of Medicine and Health Sciences, Shanghai, \\ China
}

\section{Keywords}

Obesity - Type 2 diabetes · Glucagon-like peptide-1 receptor agonist $\cdot$ Appetite regulation $\cdot$ Hypothalamic ghrelin

\begin{abstract}
Objective: To investigate the relationship of central and peripheral ghrelin during an exendin-4 (Ex-4) intervention to feeding in obese type 2 diabetic rodents. Methods: Animal models of diet-induced obesity (DIO) and type 2 diabetes were developed using male Sprague-Dawley rats fed with a high-fat diet and induced into DIO-streptozotocin diabetic rats. Ex-4 or the glucagon-like peptide-1 (GLP-1) receptor agonist exendin fragment-[9-39] (Ex-9) was intracerebroventricularly (ICV) administered. Multivariate linear regression analysis was performed to investigate potential predictors of food intake after Ex-4 administration. Results: ICV administration of Ex-4 significantly inhibited feeding and decreased weight, plasma active ghrelin, hypothalamic ghrelin, and gastric ghrelin levels. The changes in hypothalamic ghrelin and plasma ghrelin could predict the amount of 8-h average food intake. Central preadministration of Ex-9 followed by treatment with Ex-4 could inhibit the decrease in feeding at
\end{abstract}

karger@karger.com www.karger.com/ofa

Karger"

BOPEN ACCESS
(C) 2020 The Author(s)

Published by S. Karger AG, Basel

This article is licensed under the Creative Commons AttributionNonCommercial-NoDerivatives 4.0 International License (CC BYNC-ND) (http://www.karger.com/Services/OpenAccessLicense). Usage and distribution for commercial purposes as well as any distribution of modified material requires written permission.
$0.5,2$, and $8 \mathrm{~h}$. It could also inhibit the decrease in hypothalamic ghrelin at $0.5,2$, and $8 \mathrm{~h}$, as well as in plasma and gastric ghrelin at 2 and $8 \mathrm{~h}$. Conclusions: In a GLP-1 receptor-dependent manner, central and peripheral ghrelin play a vital role in the inhibition of feeding by Ex-4 administration. Hypothalamic ghrelin, but not plasma ghrelin, may be involved in central Ex-4 inhibition of feeding in the very early feeding period.

(c) 2020 The Author(s)

Published by S. Karger AG, Basel

\section{Introduction}

Glucagon-like peptide-1 (GLP-1), a gut peptide hormone secreted from intestinal L cells, plays an important role in feeding regulation and energy metabolism after food stimulation. Only $25 \%$ of GLP-1 remains active in the portal vein, and even less in the systemic blood circulation, due to rapid degradation by the DPP-4 enzyme, indicating that GLP-1 may not be able to directly activate the central GLP-1 receptor to produce satiety $[1,2]$. Ex-

Xiaoyan Chen

Department of Endocrinology

First Affiliated Hospital of Guangzhou Medical University

151 Yanjiangxi Road, Guangzhou, Guangdong 510120 (China) gzscxy@126.com

Jianhua Yan

Shanghai Key Laboratory for Molecular Imaging

Shanghai University of Medicine and Health Sciences

279 Zhouzhu Road, Shanghai 201318 (China)

Jianhua.yan@gmail.com 
endin-4 (Ex-4) is a GLP-1 receptor agonist with a half-life of several hours, which allows it to bind to the GLP-1 receptor, widely distributed throughout the brain. Previous studies have found that the central GLP-1 pathway is more effective than the peripheral GLP-1 pathway in terms of feeding regulation, manifested in dramatic inhibition of food intake with much lower doses of GLP-1 [3, 4]. It has been found that the mechanism by which GLP1 inhibits feeding may be related to increased cocaineand amphetamine-regulated transcript mRNA levels and reduced neuropeptide Y (NPY)/agouti-related peptide mRNA levels in the arcuate (ARC) nucleus [5]. In addition, Baraboi et al. [6] found that GLP-1 can activate the GLP-1 receptor in the paraventricular nucleus, indicating that GLP-1 can also regulate feeding through multiple targets in the hypothalamus. It is now known that regulation of the hypothalamic feeding and energy metabolism involves a variety of nutrients (such as blood sugar), gastrointestinal hormones (including GLP-1, ghrelin, etc.), and adjacent organ hormones (such as insulin) [7]. There may be interactions between these regulators. For example, studies have found that blood glucose may be involved in central Ex-4 inhibition of feeding, while centrally secreted GLP-1 neurons are potential targets of leptin inhibition of feeding $[8,9]$.

Growth hormone secretagogue receptors are found in many regions, especially within the hypothalamus, mainly in the ARC nucleus and ventromedial nucleus. However, peripheral acylated ghrelin, which is secreted from the stomach, reaches these areas with difficulty, due to its limited ability to pass through the blood-brain barrier [10]. One of the possible explanations is that the center also has ghrelin-producing neurons $[4,10-13]$, but this is still under debate. Reports on the distribution of neurons secreting ghrelin in the center have varied greatly between different studies [14-16]. The main issue for those who are skeptical about the existence of ghrelin neurons in the brain is that studies exhibit a large difference in specificity of the various antibodies used to demonstrate central ghrelin synthesis. However, the divergence in the distribution of ghrelin immune responses seems to reflect differences between species and ghrelin-specific epitopes rather than a poor specificity of the antibodies [17]. Kageyama et al. [18] did not rely on anti-ghrelin antibodies but used transgenic mice, while Ali et al. [19] use a perfusion radioimmunoassay. Both studies provide strong evidence that ghrelin synthesis exists at least in the hypothalamic region. Central ghrelin neurons are distributed in the ARC nucleus [17]. Many studies have shown that central ghrelin also participates in the formation of the ARC nucleus's neural feeding circuit. Ultramicroscopy immunohistochemistry studies showed that ghrelin-containing axons in the ARC nucleus have synaptic connections with NPY- or POMC-immunopositive dendrites, while NPY, orexin, and POMC axon terminals also have synaptic connections with ghrelin-containing neurons [13, 20, 21]. Ghrelin-containing neurons can also affect food intake indirectly through lateral hypothalamic orexin neurons. Pretreatment with anti-orexin-A and -orexin-B IgG in the lateral hypothalamus blocked central-ghrelin-induced feeding, followed by a further decrease in food intake with NPY receptor antagonists, suggesting that ghrelin can activate NPY or orexin signaling pathways to promote feeding [22].

Obviously, the orexigenic peptide ghrelin is at a high level, and the anorectic peptide GLP-1 is at a low level, in the early feeding period. Previous studies have found that peripheral or central administration of Ex-4 significantly inhibited food intake, accompanied by a decrease in circulating ghrelin level, and even a decrease in hypothalamic ghrelin level $[23,24]$. Ex-4 is by far the strongest peptide exerting these effects. However, it is not clear how hypothalamic and peripheral ghrelin is inhibiting food intake due to Ex-4 intervention. In this paper, we will firstly observe the changes in hypothalamic feeding-related factors and then investigate the relationship of potential factors involved during an ICV Ex-4 intervention in obese diabetic rodents.

\section{Materials and Methods}

Drugs and Chemicals

Streptozotocin (STZ), Ex-4, Ex-9, paraformaldehyde, the ELISA kit for acylated ghrelin, and obestatin were purchased from SigmaAldrich (St. Louis, MO, USA). The Rabbit Anti-Ghrelin (Rat, Mouse) Antibody was from Phoenix Pharmaceuticals Inc. (Belmont, CA, USA). The GT Vision III Anti-Mouse/Rabbit Universal Immunohistochemistry Test Kit was from DAKO (Glostrup, Denmark). The kits for blood glucose, triglyceride, cholesterol, and insulin were purchased from BHKT Co. (Beijing, China).

Animals

A total of 200 male 3-week-old SPF Sprague-Dawley rats weighing about 50-60 g were purchased from the Guangdong Animal Experimental Center. All rats were kept in a 12/12-h light-dark cycle environment at room temperature $\left(18-25^{\circ} \mathrm{C}\right)$ and a relative humidity of $50-80 \%$. They were randomly divided into two groups: 10 rats were the control group, which was fed with normal chow diet ( $67 \%$ carbohydrate, $21 \%$ protein, and $12 \%$ fat); 190 rats were fed with a high-fat diet (41\% carbohydrate, $19 \%$ protein, and $40 \%$ fat). Both groups were given free access to food and water. Food intake was recorded every day and body weight was monitored every other day. 
After 6 weeks of high-fat diet feeding, those rats with a weight gain $20 \%$ greater than the average body weight of the control group were classified as the obese group, and the others were classified as the non-obese group [25]. In all, 178 obese and 12 non-obese rats were obtained; 41 obese rats entered the diet-induced obesity (DIO) group, and the remaining 137 obese rats were further divided by randomly inducing diabetes. The rats fasted for $12 \mathrm{~h}$ before injection. Freshly prepared $1 \% \mathrm{STZ}$ at $35 \mathrm{mg} / \mathrm{kg}(0.1 \mathrm{mmol} / \mathrm{L}$ citrate buffer with $\mathrm{pH}$ 4.2) was intraperitoneally (IP) injected. Rats with plasma glucose levels exceeding $16.6 \mathrm{mmol} / \mathrm{L}$ were classified as diabetic rats. Only 5 rats died, and the remaining 132 DIO-STZ rats were successfully modeled. They were randomly divided into an Ex-4 group $(n=50)$, an Ex-9 group $(n=40)$, and a vehicle or NS group $(n=40)$ (Fig. 1).

\section{ICV Cannulation}

Anesthetized with $10 \%$ chloral hydrate, the rats' head was fixed on the brain stereotaxic instrument. A triangle- or heart-shaped incision located 3-5 $\mathrm{mm}$ under the line connecting the two ears was made. Referring to the Paxinos and Watson rat brain stereotaxic coordinates and related literature $[26,27]$, the 3 rd ventricle was located $2 \mathrm{~mm}$ behind the bregma on the sagittal suture and $7.5 \mathrm{~mm}$ below the surface of the skull. Holes were drilled at the entry point and a screw placed, and the three holes formed an equilateral triangle. After the screw was placed, the trocar was slowly implanted. The ICV catheter, screw, and skull were tightly bonded with dental cement. After the operation, the rats were kept in a single cage, fed freely, and then injected with $80,000 \mathrm{U}$ of penicillin for 3 days to prevent infection; $10 \mathrm{ng}$ angiotensin II (about $1 \mu \mathrm{L}$ ) was injected via the catheter. Water consumption of the rats exceeding $30 \mathrm{~mL}$ within $30 \mathrm{~min}$ was identified successfully. All rats had their catheters installed successfully, and the 3rd-ventricle tubes were unobstructed.

\section{Jugular Intubation}

The operation was conducted 1 week before the formal experiment. The rats were anesthetized by $10 \%$ chloral hydrate. A longitudinal incision about $1.5 \mathrm{~cm}$ long was made at the right side of the midline of the neck. The muscles and fasciae were bluntly separated by forceps and the jugular vein was stripped out. The distal part of the jugular vein was ligated. After the blood vessel was gently held up, a $45^{\circ}$ oblique incision was made. The cannula was inserted from the incision to the proximal end (about $3.5 \mathrm{~cm}$ length). The catheter and the blood vessel were ligated and fixed. The catheter was taken from the anterior cervical incision through the skin to the incision (about $0.5 \mathrm{~cm}$ ) on the back of the nape, and the connective tissue and skin were sutured. The rats were housed in single cages after the operation. Two rats died during the operation due to acute blood loss.

\section{Feeding}

The rats were fed individually for $24 \mathrm{~h}$ with food deprivation but no water deprivation. A fasting blood sample was taken through the jugular vein cannula at the beginning of the experiment. For the ICV injection experiment, the total volume administered was $5 \mu \mathrm{L}$ for each rat. Ex-4 (0.1 $\mu \mathrm{g})$ [28], pretreated Ex-9 (50 $\mu \mathrm{g})$ [23], or vehicle ( $5 \mu \mathrm{L}$ of saline) was administered via the catheter at 6:00 p.m. Food particles weighing $50 \mathrm{~g}$ contained in a preprepared small can were placed in the cage. Immediately after ICV injection, the amount of remaining food and the blood sample at the corresponding time point were collected $30 \mathrm{~min}$ and 2, 8, and $24 \mathrm{~h}$ after the beginning of the test.

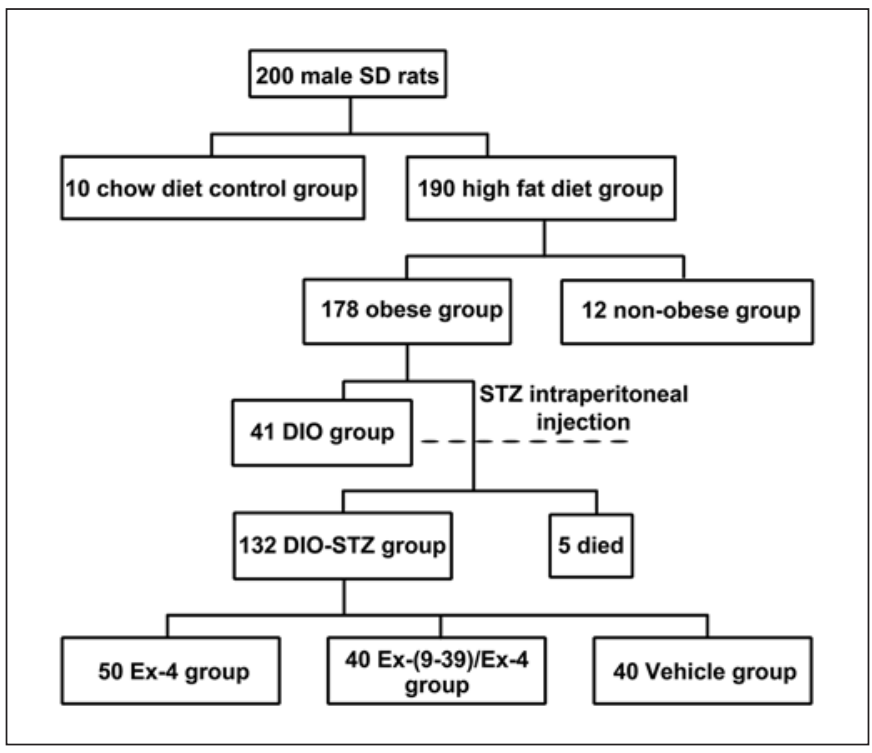

Fig. 1. Study flowchart of rat group formation. STZ, streptozotocin; DIO, diet-induced obesity; Ex, exendin.

\section{Plasma Analysis}

Blood glucose, triglyceride, cholesterol, insulin, acylated ghrelin, and obestatin were measured according to the kit's manual. Plasma samples were kept at $-20^{\circ} \mathrm{C}$ until assayed after centrifugation.

\section{Tissue Collection}

After being anesthetized, the rats were fixed on the operating table for cardiac perfusion. Brain and stomach fundus specimens were collected. The samples were fixed separately with $1 \%$ paraformaldehyde for 6-12 h. The ventral surface of the brain was fixed upward on a special brain mold, and the brain regions were separated [26]. The center point of the line connecting the gray nodules with the optic chiasm was used to determine the hypothalamic tissue, from which 3-mm-thick tissue specimens were cut in the coronary plane. They were taken for routine dehydration, transparency, and waxing, embedded, and sliced on a glass slide at a thickness of $4 \mu \mathrm{m}$, followed by storage at room temperature for $4 \mathrm{~h}$ at $37^{\circ} \mathrm{C}$.

\section{Immunocytochemistry}

The stomach or hypothalamus glass slides were baked at a baking temperature of $60^{\circ} \mathrm{C}$ for $1-1.5 \mathrm{~h}$ and naturally cooled afterwards. The specimens were deparaffinized in xylene at room temperature for $20 \mathrm{~min}$ and then rehydrated using an alcohol gradient. The slides were incubated in $0.01 \mathrm{~mol} / \mathrm{L}$ boiling sodium citrate buffer at $\mathrm{pH} 6.0$ for $15 \mathrm{~min}$ and then cooled at room temperature to reveal the antigen. The samples were incubated with $3 \% \mathrm{H}_{2} \mathrm{O}_{2}$ for $20 \mathrm{~min}$ to inhibit peroxidase activity, and then blocked with $5 \%$ goat serum and kept at room temperature for $30 \mathrm{~min}$. The primary rabbit anti-rat ghrelin antibody was added, followed by incubation for $24 \mathrm{~h}$ at $4^{\circ} \mathrm{C}$. After having been washed 3 times with PBS, the slides were incubated in the secondary antibody for $30 \mathrm{~min}$ at $37^{\circ} \mathrm{C}$. After 3 washes with PBS, the slides were stained with DAB for $5 \mathrm{~min}$ and counterstained with hematoxylin for $45 \mathrm{~s}$, then 
Table 1. Characteristics of the DIO-STZ and DIO rats at baseline

\begin{tabular}{lccc}
\hline & $\begin{array}{l}\text { DIO-STZ Ex-4 } \\
(n=50)\end{array}$ & $\begin{array}{l}\text { DIO-STZ vehicle } \\
(n=40)\end{array}$ & $\begin{array}{l}\text { DIO } \\
(n=40)\end{array}$ \\
\hline Weight, g & $415.10 \pm 26.22$ & $410.22 \pm 25.47$ & $444.42 \pm 49.29$ \\
Fasting blood glucose, mmol/L & $11.29 \pm 4.18^{*}$ & $11.11 \pm 3.96^{*}$ & $6.54 \pm 1.66$ \\
Postprandial blood glucose, mmol/L & $24.01 \pm 4.10^{*}$ & $23.87 \pm 3.71^{*}$ & $8.07 \pm 1.30$ \\
Fasting insulin, mU/L & $75.88 \pm 16.83$ & $74.24 \pm 11.51$ & $79.36 \pm 18.72$ \\
Triglyceride, $\mathrm{mmol} / \mathrm{L}$ & $1.87 \pm 0.38$ & $1.82 \pm 0.43$ & $1.34 \pm 0.37$ \\
Cholesterol, mmol/L & $3.45 \pm 1.14$ & $3.37 \pm 0.89$ & $3.57 \pm 0.56$ \\
Ghrelin, $\mathrm{pg} / \mathrm{mL}$ & $28.95 \pm 4.24$ & $28.73 \pm 3.87$ & $30.81 \pm 0.34$ \\
Obestatin, $\mathrm{ng} / \mathrm{mL}$ & $24.15 \pm 3.57$ & $24.10 \pm 3.44$ & $26.95 \pm 5.00$ \\
\hline
\end{tabular}

STZ, streptozotocin; DIO, diet-induced obesity; Ex, exendin. * Represents significant difference compared with DIO group $(p<0.05)$.

rinsed with running water for $5 \mathrm{~min}$. The sections were finally processed by alcohol gradient dehydration, xylene soaking, and resin blocking. Positive expression of ghrelin in the gastric mucosa or hypothalamus was observed under a high-power lens. Three nonoverlapping visual fields were randomly selected. The integral absorbance of each field's positive staining was determined by Image-Pro Plus 6.0 software (integrated absorbance = staining intensity $\times$ staining area). The calculated average value was used as the quantitative index of ghrelin expression in the gastric mucosa or hypothalamus of the section.

\section{Statistical Analyses}

Statistical analyses were performed using the SPSS 19.0 software. The measured data are expressed as mean \pm standard deviation. The independent-samples $t$ test was used to compare differences between two groups, and the paired $t$ test was used to compare differences between baseline (pre-Ex- 4 administration) and measurements after Ex-4 administration at 8 h. One-way ANOVA was applied for the comparison between three groups at each time point or time period. Changes in independent variables between the DIO-STZ Ex-4, DIO-STZ vehicle, and DIO control group, or between the Ex-4, Ex-9/Ex-4, and NS group, were analyzed with repeated-measures ANOVA followed by Duncan's post hoc testing. Pearson's linear correlation test or Spearman's rank-order test was used to obtain correlations between the change in food intake and feeding-related factors according to normality examination by Shapiro-Wilk analysis. Associations between changes in average food intake and potential predictor variables were evaluated using multivariable stepwise linear regression models. $p<0.05$ was considered statistically significant.

\section{Results}

Baseline Characteristics of the DIO-STZ and DIO Rats Both the fasting and the postprandial blood glucose levels of the DIO-STZ Ex-4 and DIO-STZ vehicle groups were significantly higher than those of the DIO group $(p<0.05)$. The weight of the rats in the DIO-STZ Ex-4,
DIO-STZ vehicle, and DIO groups was significantly higher (around 24-29\%) than in the non-obese group $(311.77 \pm 25.38 \mathrm{~g})$ (Table 1$)$.

\section{Effects of Central Administration of Ex-4 on Food Intake and Body Weight}

A statistical significance of cumulative food intake was found in the Ex-4 (ICV), NS (ICV), and Ex-4 (IP) groups of DIO rats, which revealed the dramatic inhibitory effect on feeding of Ex-4 through the ICV route (Fig. 2A). The DIO-STZ Ex-4 group had a lower average food intake $(2.12 \pm 0.66 \mathrm{~g})$ than the DIO-STZ vehicle group (5.41 \pm $0.96 \mathrm{~g})$ and the DIO group $(6.63 \pm 0.98 \mathrm{~g})(p=0.008$ and $p=0.001$, respectively) (Fig. 2B). The 24 -h weight loss in the DIO-STZ Ex-4 group $(-10 \pm 9.97 \mathrm{~g})$ was greater than that in the DIO-STZ vehicle group $(-0.125 \pm 7.68 \mathrm{~g})(t=$ $-2.219, p=0.044$ ) (Fig. 2C).

\section{Effects of Central Administration of Ex-4 on Blood}

Glucose, Insulin, Obestatin, and Ghrelin Levels

The DIO-STZ Ex-4 group had a higher blood glucose level than the DIO control group ( $p=0.000)$; the difference between the DIO-STZ Ex-4 group (14.76 \pm 0.72 $\mathrm{mmol} / \mathrm{L})$ and the DIO-STZ vehicle group (13.80 \pm 0.84 $\mathrm{mmol} / \mathrm{L}$ ) was not significant $(p=0.553)$. Furthermore, the DIO-STZ Ex-4 group showed only a slight increase compared to the DIO-STZ vehicle group after $0.5 \mathrm{~h}$ (Fig. 3A). There was no significant difference in baseline insulin level between the three groups $(F=3.01, p=$ 0.071). However, the insulin levels of the DIO-STZ vehicle and DIO control groups were surprisingly shown to have a tendency to increase, and a significant difference between the DIO-STZ Ex-4 and the DIO control group was even observed at 2 and $8 \mathrm{~h}\left(p_{2 \mathrm{~h}}=0.015\right.$ and $p_{8 \mathrm{~h}}=$ 


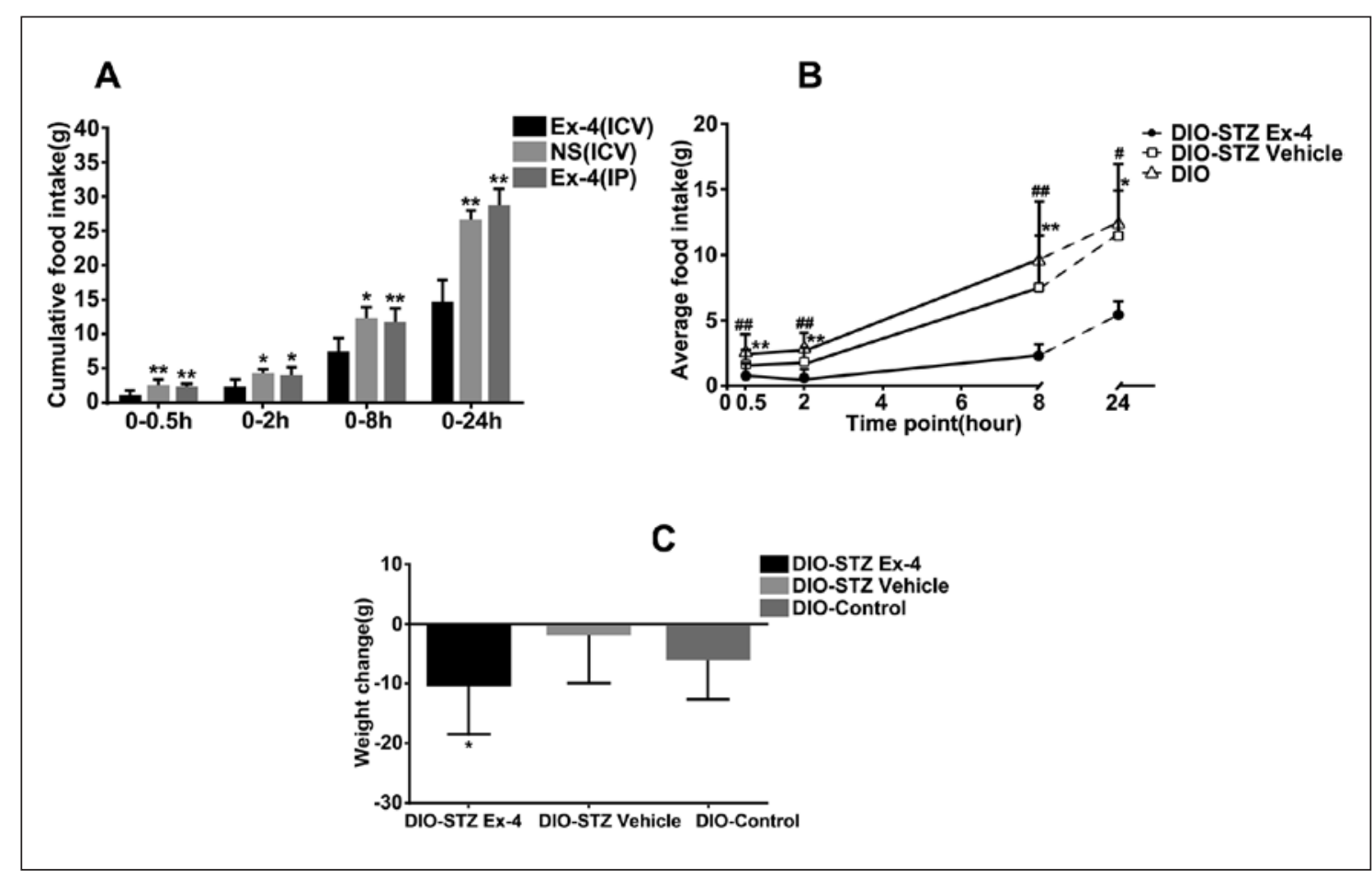

Fig. 2. Central effects of Ex-4 on food intake and body weight. A Cumulative food intake. B Average food intake. $\mathrm{C}$ Weight change. DIO rats were used in $\mathbf{A}$ and used as controls (DIO-control) in $\mathbf{B}$ and $\mathbf{C}$. Values are means \pm SEM ( $n=50$ for DIO-STZ Ex-4 group and $n=40$ for DIO-STZ vehicle and DIO groups). ${ }^{*} p<0.05,{ }^{* *} p<0.01$ compared to DIO-STZ vehicle or Ex-4 (ICV) group; ${ }^{*} p<0.05,{ }^{\# \#} p<0.01$ compared to DIO-control. STZ, streptozotocin; DIO, diet-induced obesity; Ex, exendin; ICV, intracerebroventricular; IP, intraperitoneal.

0.010) (Fig. 3B). The blood obestatin level in the DIOSTZ Ex-4 group was shown to be significantly lower than that in the DIO-STZ vehicle and the DIO control group at $0.5 \mathrm{~h}$ ( $p=0.040$ and $p=0.001$, respectively) (Fig. 3C). The differences in plasma ghrelin, hypothalamic ghrelin, and gastric ghrelin levels between the DIO-STZ Ex-4, DIO-STZ vehicle, and DIO control groups were statistically significant $\left(F_{\text {plasma ghrelin }}=26.594, p_{\text {plasma ghrelin }}=\right.$ $0.000 ; F_{\text {hypothalamic ghrelin }}=50.401, p_{\text {hypothalamic ghrelin }}=0.000$; $\left.F_{\text {gastric ghrelin }}=4.671, p_{\text {gastric ghrelin }}=0.021\right)$. The DIO-STZ Ex-4 group had lower plasma ghrelin, hypothalamic ghrelin, and gastric ghrelin levels than the DIO-STZ vehicle group $\left(p_{\text {plasma ghrelin }}=0.000 ; p_{\text {hypothalamic ghrelin }}=0.000\right.$; $\left.p_{\text {gastric ghrelin }}=0.037\right)$ and the DIO control group ( $p_{\text {plas- }}$ ma ghrelin $=0.000 ; p_{\text {hypothalamic ghrelin }}=0.000 ; p_{\text {gastric ghrelin }}=$ 0.008). The levels of ghrelin in the three groups had transiently decreased by $0.5 \mathrm{~h}$ and then gradually increased over the subsequent time points with Ex-4. At the time point of $0.5 \mathrm{~h}$, only hypothalamic ghrelin levels showed a significant difference, i.e., the hypothalamic ghrelin level in the DIO-STZ Ex-4 group was lower than that in the DIO-STZ vehicle group $(p=0.039)$ or the DIO control group $(p=0.001)$. At 2 and $8 \mathrm{~h}$, the DIO-STZ Ex- 4 group had significantly lower plasma, hypothalamic, and gastric ghrelin levels than the DIO-STZ vehicle group or the DIO control group ( $p<0.05$ or 0.01 at different time points) (Fig. 3D-F).

Differences in Blood Glucose, Insulin, Obestatin, and Ghrelin Levels between before and after ICV Ex-4 Administration

Based on a study, food intake is inhibited for at least 8 $\mathrm{h}$ after ICV Ex- 4 administration, so $8 \mathrm{~h}$ was chosen as the observation time node in our study [4]. Except for blood glucose levels, significant decreases in plasma insulin, plasma obestatin, and plasma active ghrelin, hypothalamic ghrelin and gastric ghrelin levels were seen in DIO-STZ rats after ICV Ex-4 administration at $8 \mathrm{~h}$ as compared to baseline levels $(p<0.05)$. Thus, all these parameters were further investigated (Fig. 4). 


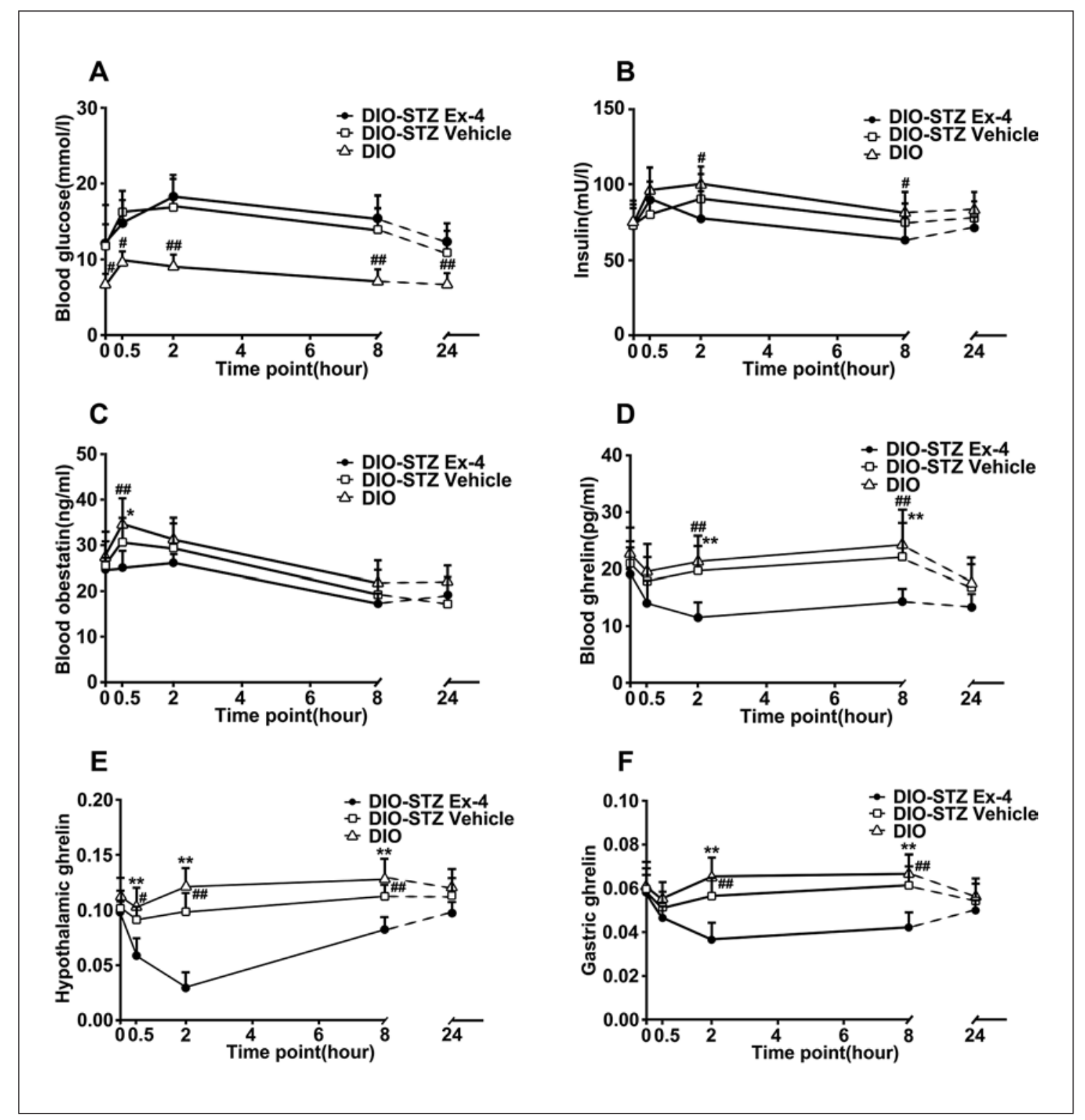

Fig. 3. Central effects of Ex-4 on blood glucose (A), insulin (B), blood obestatin (C), plasma ghrelin (D), hypothalamic ghrelin (E), and gastric ghrelin (F) levels. DIO rats were used as controls (DIO-control). Values are means \pm SEM ( $n=50$ for DIO-STZ Ex-4 group and $n=40$ for DIO-STZ vehicle and DIO groups). ${ }^{*} p<0.05$, ${ }^{* *} p<0.01$ compared to DIO-STZ vehicle; ${ }^{\#} p<0.05,{ }^{\# \#} p<0.01$ compared to DIO-control. STZ, streptozotocin; DIO, diet-induced obesity; Ex, exendin.

Predictors of Food Intake of DIO-STZ Rats with Ex-4 Administration

Except for blood glucose $(r=0.431, p=0.286)$, significant positive correlations between change in average food intake and blood insulin, plasma ghrelin, gastric ghrelin, hypothalamic ghrelin, and blood obestatin were detected. Thus, the following indicators were included in the models: $\Delta$ blood insulin, $\Delta$ plasma ghrelin, $\Delta$ gastric ghrelin, $\Delta$ hypothalamic ghrelin, and $\Delta$ blood obestatin. Given that food intake inevitably is a positive number and considering the trend for a decline in candidate parameters during Ex-4 administration, we used the absolute value of the parameter change to ensure that the objective relationship and trend can be reflected. Significant pre- 
Fig. 4. Differences in blood glucose (A), insulin (B), plasma ghrelin (C), obestatin (D), hypothalamic ghrelin (E), and gastric ghrelin (F) levels between before and after ICV Ex-4 administration. DIO-STZ rats were used. Values are means \pm SEM. STZ, streptozotocin; DIO, diet-induced obesity; Ex, exendin; ICV, intracerebroventricular.
4A

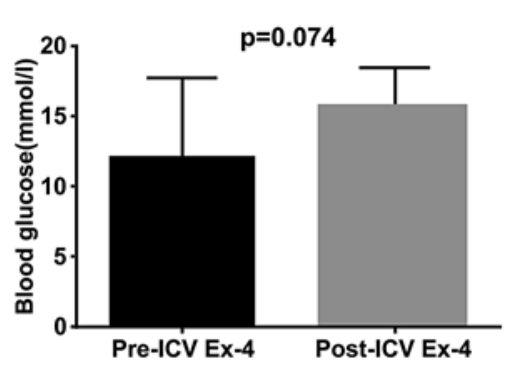

4C

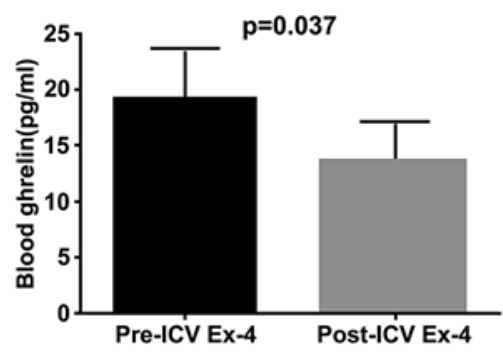

4E

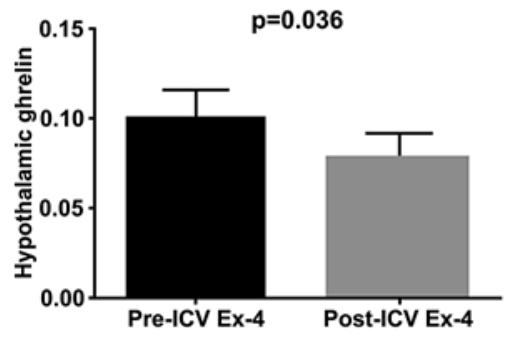

4B

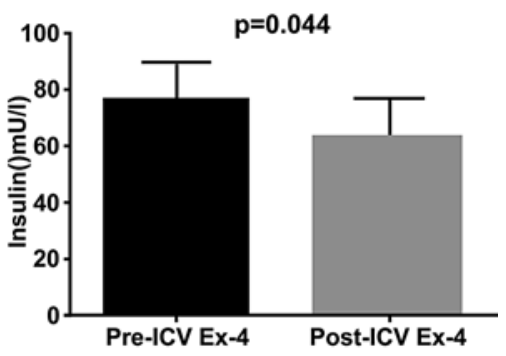

4D

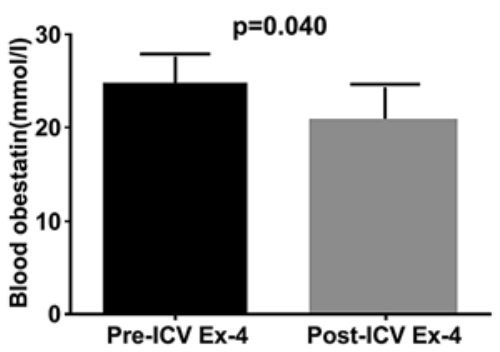

4F

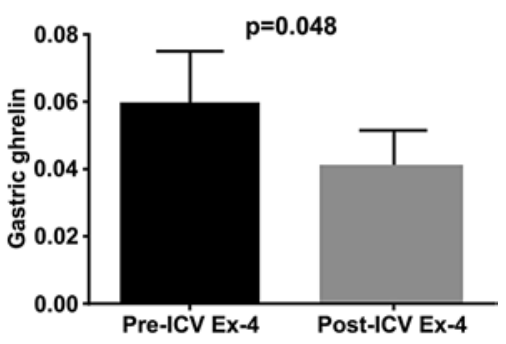

dictors of average food intake were $\Delta$ hypothalamic ghrelin and $\Delta$ plasma ghrelin $(p=0.013$ and $p=0.030$, respectively). We next used the specific GLP-1 receptor antagonist Ex-9 to further explore whether the GLP-1 receptor mediated the changes in hypothalamic and plasma ghrelin, which provided a basis for understanding the time difference in the anorexigenic effects of hypothalamic ghrelin and plasma ghrelin under Ex-4 administration (Table 2).

\section{Effects of Central Pre-Administration of Ex-9}

Followed by Treatment with Ex-4 on Food Intake and Ghrelin Levels

The Ex-4 group had a lower average food intake than the Ex-9/Ex-4 group and the NS group ( $p=0.043$ and $p=$ 0.004 , respectively) (Fig. 5A). Statistically significant dif- ferences were detected in plasma ghrelin, hypothalamic ghrelin, and gastric ghrelin between the Ex-4, Ex-9/Ex-4, and NS groups $\left(F_{\text {plasma ghrelin }}=15.73, p_{\text {plasma ghrelin }}=0.000\right.$; $F_{\text {hypothalamic ghrelin }}=38.479, p_{\text {hypothalamic ghrelin }}=0.001 ; F_{\text {gastric }}$ ghrelin $\left.=10.414, p_{\text {gastric ghrelin }}=0.001\right)$. The differences in plasma ghrelin, hypothalamic ghrelin, and gastric ghrelin at 2 and $8 \mathrm{~h}$ between the three groups were statistically significant $\left(F_{2 \mathrm{~h} \text { plasma ghrelin }}=9.641, p_{2 \mathrm{~h} \text { plasma ghrelin }}=0.001\right.$; $F_{2 \mathrm{~h} \text { hypothalamic ghrelin }}=9.637, p_{2 \mathrm{~h} \text { hypothalamic ghrelin }}=0.001$; $F_{2 \mathrm{~h} \text { gastric ghrelin }}=6.905, p_{2 \mathrm{~h} \text { gastric ghrelin }}=0.005 ; F_{8 \mathrm{~h} \text { plasma ghre- }}$ lin $=9.544, p_{8 \mathrm{~h} \text { plasma ghrelin }}=0.001 ; F_{8 \mathrm{~h} \text { hypothalamic ghrelin }}=$ $10.09, p_{8 \mathrm{~h} \text { hypothalamic ghrelin }}=0.001 ; F_{8 \mathrm{~h} \text { gastric ghrelin }}=7.593$, $\left.p_{8 \mathrm{~h} \text { gastric ghrelin }}=0.003\right)$. The differences in plasma ghrelin, hypothalamic ghrelin, and gastric ghrelin between the Ex-9 group and the NS group were statistically significant at multiple time points $\left(p_{0.5 \mathrm{~h} \text { hypothalamic ghrelin }}=0.047 ; p_{2 \mathrm{~h}}\right.$ 
Table 2. Simple correlation and multiple stepwise linear regression analysis of food intake for DIO-STZ rats following Ex-4 administration (changes in average food intake as dependent variable)

\begin{tabular}{|c|c|c|c|c|}
\hline \multirow[t]{2}{*}{ Independent variable } & \multicolumn{2}{|c|}{ Univariate } & \multicolumn{2}{|l|}{ Stepwise } \\
\hline & $R$ & $p$ & standardized $\beta$ & $p$ \\
\hline $\mid \Delta$ blood insulin $\mid$ & 0.714 & 0.047 & - & - \\
\hline | $\Delta$ blood ghrelin $\mid$ & 0.734 & 0.038 & 0.700 & 0.013 \\
\hline $\mid \Delta$ gastric ghrelin $\mid$ & 0.730 & 0.040 & - & - \\
\hline $\mid \Delta$ hypothalamic ghrelin $\mid$ & 0.750 & 0.032 & 0.556 & 0.030 \\
\hline $\mid \Delta$ blood obestatin $\mid$ & 0.715 & 0.046 & - & - \\
\hline
\end{tabular}

$\Delta$ refers to the change between before ( $0 \mathrm{~min})$ and after Ex-4 administration ( $8 \mathrm{~h})$. STZ, streptozotocin; DIO, diet-induced obesity; Ex, exendin.

hypothalamic ghrelin $=0.049, p_{2 \mathrm{~h} \text { plasma ghrelin }}=0.036, p_{2 \mathrm{~h} \text { gastric }}$ ghrelin $=0.046 ; p_{8 \mathrm{~h} \text { plasma ghrelin }}=0.043, p_{8 \mathrm{~h} \text { hypothalamic ghrelin }}=$ 0.049 ). However, only the hypothalamic ghrelin level at $0.5 \mathrm{~h}$ in the Ex-4 group $(0.060 \pm 0.010)$ was significantly lower than that in the Ex-9/Ex-4 group $(0.079 \pm 0.016)$ and the NS group $(0.090 \pm 0.020)(p=0.034$ and $p=0.000$, respectively) (Fig. 5B-D).

\section{Discussion}

Our study found that ICV administration of Ex-4 significantly inhibited food intake, achieved weight loss, and reduced plasma, gastric and hypothalamic ghrelin in obese diabetic rats. Linear regression analysis showed that changes in plasma ghrelin and hypothalamic ghrelin, but not in plasma insulin and obestatin, were determinants of average food intake during $8 \mathrm{~h}$. Using Ex-9 for receptor blockade experiments, the changes in average food intake, hypothalamic ghrelin, and plasma ghrelin were mediated by the GLP-1 receptor. Only hypothalamic ghrelin, but not plasma ghrelin, at $0.5 \mathrm{~h}$ may be related to change in food intake under Ex-4 administration.

Obestatin, a different peptide from ghrelin, is encoded by the same ghrelin gene. Our study found that the level of blood obestatin in the DIO-STZ Ex-4 group was still inhibited after $30 \mathrm{~min}$ of Ex-4 administration. Linear regression analysis did not find any significant correlation between change in feeding and plasma obestatin, and Ex-4 did not seem to be able to directly inhibit the plasma obestatin level to reduce food intake. The change may suggest an adaptive or secondary change when undergoing starvation for $24 \mathrm{~h}$. A previous study also found a decrease in plasma obestatin 30 min after oral administra- tion of the DPP-4 inhibitor vildagliptin, which seems to support our observation [29].

Our study found that ICV Ex-4 injection significantly increased insulin secretion at $0.5 \mathrm{~h}$, but that insulin secretion was even lower than that of the control group at 2 and $8 \mathrm{~h}$, which is consistent with a previous study [4]. Blood glucose did not decrease after Ex-4 administration. This suggests that direct ICV administration of Ex-4 affects islet function, contrary to what is seen with peripheral administration of GLP-1. The inhibition of insulin secretion induced by central administration of GLP-1 has also been observed in some studies, which suggests that this paradoxical effect may be related to GLP-1 stimulation of sympathetic nervous system activity, as manifested in hyperadrenalinemia [28].

Based on the observation experiment, even though the linear regression model had preliminarily further clarified the role of hypothalamic and plasma ghrelin levels in the effect of feeding inhibition by Ex-4, the characteristics of the specific action of these two factors remained unknown. Furthermore, Ex-9 was used for receptor blockade experiments. It has been reported that Ex-9 itself can reduce ghrelin levels [4]. Our observation also suggested that in the Ex-9 group, plasma, hypothalamic, and gastric ghrelin levels were at some time points significantly lower than in the NS group. However, even then the Ex-4 group was still dramatically different from the Ex-9 group under these conditions, suggesting that the inhibiting effect of central Ex-4 administration on feeding could still be proved to be mediated by the GLP-1 receptor.

Unlike at other time points, in the early 30-min feeding period, only hypothalamic ghrelin, but not peripheral ghrelin, was responsible for the change in feeding, suggesting that hypothalamic ghrelin is involved in the inhi- 


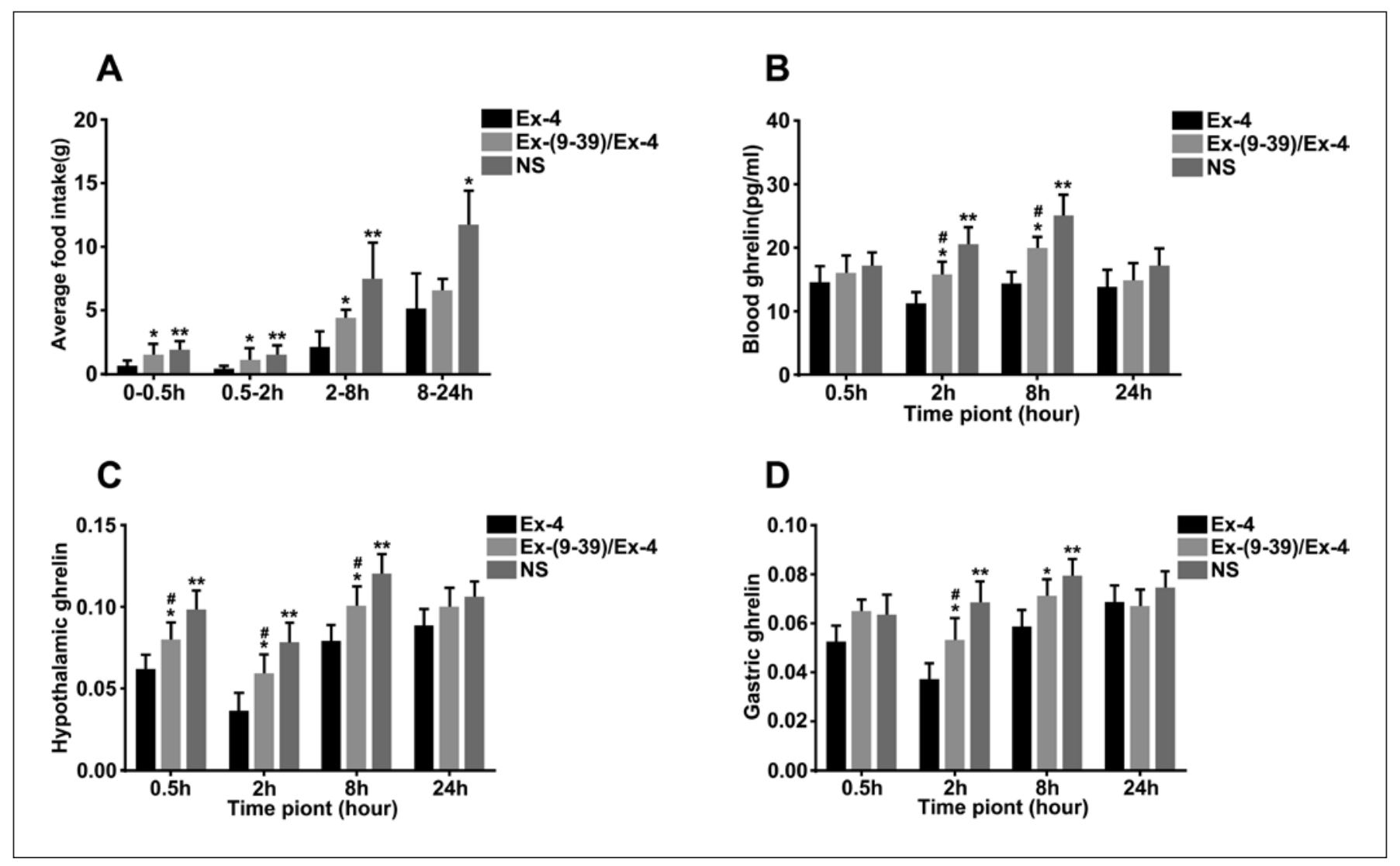

Fig. 5. Central effects of Ex-9 on food intake and ghrelin levels. A Average food intake. B Plasma ghrelin. C Hypothalamic ghrelin. D Gastric ghrelin. Values are means \pm SEM ( $n=50$ for Ex-4 group and $n=40$ for Ex-9/Ex-4 and NS groups). ${ }^{*} p<0.05,{ }^{* *} p<0.01$ compared to Ex-4 group; ${ }^{*} p<0.05$ compared to NS group. Ex, exendin.

bition of feeding induced by ICV Ex-4 administration at least in the very early stage. Our findings are consistent with that of Hong et al. [24] - that is, administration of Ex-4 into the 3rd ventricle can inhibit the expression of ghrelin in the hypothalamus, stomach, and plasma - but their study did not explore the relationship between them, even though there are neurohumoral connections between the brain and the gastrointestinal tract. Therefore, our results can lead to at least two different interpretations. On the one hand, ICV Ex-4 administration could activate ghrelin-producing neurons adjacent to the 3rd ventricle to induce feeding, and then Ex-4 may permeate the blood-brain barrier to further stimulate ghrelin-producing cells in the stomach to subsequently regulate feeding $[30,31]$. On the other hand, central Ex-4 administration may regulate gastric ghrelin expression directly through the neural signals transmitted by the vagal nerve, which in turn regulates feeding [32-34]. The study by Pérez-Tilve et al. [4] showed that plasma ghrelin began to decrease significantly after 30 min of ICV Ex-4 administration. Moreover, ICV administration of oxyntomodulin, which also acts on the GLP-1 receptor and inhibits feeding behavior, significantly reduced the secretion of ghrelin in the stomach for about $60 \mathrm{~min}$, which provides direct evidence that central administration of Ex-4 probably inhibits the secretion of gastric ghrelin through an osmotic mechanism [35]. Furthermore, one study showed that neuroactive drugs exerted immediate and significant effects on the synthesis of ghrelin by excitatory autonomic nerves less than 15 min after administration, which is obviously even earlier than the 30 min we observed [33]. Nerve conduction is calculated in milliseconds and neurosecretion occurs very quickly $[36,37]$. Our study found no changes in peripheral plasma ghrelin at $30 \mathrm{~min}$, which may further support the notion that the vagal nerves are not involved in inhibition of gastric ghrelin by central Ex-4 administration. Further research is needed to confirm the above hypothesis. 
Our study has some limitations. First, to confirm the role of hypothalamic ghrelin in the inhibitory food intake effect of central Ex-4 administration, our study only investigated the changes in hypothalamic ghrelin and food intake with Ex-4 activating the GLP-1 receptor or Ex-9 blocking the GLP-1 receptor. It lacks results as to whether the subsequent pathways of hypothalamic ghrelin are blocked by ghrelin receptor blockers in rats in vivo, which needs further studies. Second, as mentioned above, there are many methods for detecting central ghrelin, and the immunohistochemical methods we used are not the most sensitive ones. The results using different kits may vary depending on differences in the design of binding to various antigenic epitopes. Furthermore, we did not measure hypothalamic ghrelin mRNA and growth hormone secretagogue receptor levels; thus, we might not fully understand the expression and function of the hypothalamic ghrelin system. Third, the evaluation indicators used to predict average food intake in this study are very limited, and further research may need to include more important potential control variables.

\section{Conclusions}

In a GLP-1 receptor-dependent manner, central and peripheral ghrelin levels play a role in the inhibition of feeding by Ex-4 administration. Hypothalamic ghrelin is involved in central Ex-4-induced inhibition of feeding in the very early feeding period (within $30 \mathrm{~min}$ ), and subsequent longer-time feeding inhibition may be achieved by both factors and not only the target of ghrelin's action. Our study highlights the important early potential role of hypothalamic ghrelin in inhibition of the feeding behavior of obese diabetic rats with GLP-1 receptor agonist intervention, which may provide a novel target for treatment of obesity and type 2 diabetes mellitus.

\section{Acknowledgments}

The authors thank Qi Wan, Qiao Zou, Changbing Chen, Bin $\mathrm{He}$, and Sujun Kuang for their expert technical assistance in the hard work of feeding testing and tissue collection procedures.

\section{Statement of Ethics}

All procedures met the requirements of the laboratory animal operation and animal welfare principles of the Animal Experimental Center of Guangzhou Medical University. The study was authorized by the Animal Ethics Committee of Guangzhou Medical University.

\section{Conflict of Interest Statement}

The authors declare no conflict of interest.

\section{Funding Sources}

This study received grants from the Science and Technology Foundation of Guangzhou City (201607010369) and the Foundation of Science and Technology Department of Guangdong Province (2016A020215169).

\section{Author Contributions}

Xiaoyan Chen conceived the project. Ke Lu, Xuelian Deng, and Juan Long performed the experiments, analyzed the data, and wrote the manuscript. Xiaoyan Chen and Jianhua Yan critically reviewed the manuscript. All authors have approved the final manuscript as submitted.

\section{References}

1 Kanoski SE, Hayes MR, Skibicka KP. GLP-1 and weight loss: unraveling the diverse neural circuitry. Am J Physiol Regul Integr Comp Physiol. 2016 May;310(10):R885-95.

2 D'Alessio D. Is GLP-1 a hormone: whether and when? J Diabetes Investig. 2016 Apr;7(S1 Suppl 1):50-5.

3 NamKoong C, Kim MS, Jang BT, Lee YH, Cho YM, Choi HJ. Central administration of GLP-1 and GIP decreases feeding in mice. Biochem Biophys Res Commun. 2017 Aug; 490(2):247-52.

Hypothalamic Ghrelin in Obesity
4 Pérez-Tilve D, González-Matías L, AlvarezCrespo M, Leiras R, Tovar S, Diéguez C, et al. Exendin-4 potently decreases ghrelin levels in fasting rats. Diabetes. 2007 Jan;56(1):143-51.

5 Seo S, Ju S, Chung H, Lee D, Park S. Acute effects of glucagon-like peptide-1 on hypothalamic neuropeptide and AMP activated kinase expression in fasted rats. Endocr J. 2008 Oct;55(5):867-74.

6 Baraboi ED, St-Pierre DH, Shooner J, Timofeeva E, Richard D. Brain activation following peripheral administration of the GLP-1 receptor agonist exendin-4. Am J Physiol Regul Integr Comp Physiol. 2011 Oct;301(4):R1011-24.
$7 \mathrm{Yu}$ JH, Kim MS. Molecular mechanisms of appetite regulation. Diabetes Metab J. 2012 Dec;36(6):391-8.

8 Burmeister MA, Ayala J, Drucker DJ, Ayala JE Central glucagon-like peptide 1 receptor-induced anorexia requires glucose metabolismmediated suppression of AMPK and is impaired by central fructose. Am J Physiol Endocrinol Metab. 2013 Apr;304(7):E677-85.

9 Goldstone AP, Mercer JG, Gunn I, Moar KM, Edwards CM, Rossi M, et al. Leptin interacts with glucagon-like peptide-1 neurons to reduce food intake and body weight in rodents. FEBS Lett. 1997 Sep;415(2):134-8. 
10 Cabral A, Valdivia S, Fernandez G, Reynaldo M, Perello M. Divergent neuronal circuitries underlying acute orexigenic effects of peripheral or central ghrelin: critical role of brain accessibility. J Neuroendocrinol. 2014 Aug; 26(8):542-54

11 Gnanapavan S, Kola B, Bustin SA, Morris DG, McGee P, Fairclough P, et al. The tissue distribution of the mRNA of ghrelin and subtypes of its receptor, GHS-R, in humans. J Clin Endocrinol Metab. 2002 Jun;87(6):298891.

12 Abizaid A,LiuZW, AndrewsZB, Shanabrough M, Borok E, Elsworth JD, et al. Ghrelin modulates the activity and synaptic input organization of midbrain dopamine neurons while promoting appetite. J Clin Invest. 2006 Dec; 116(12):3229-39.

13 Cowley MA, Smith RG, Diano S, Tschöp M, Pronchuk N, Grove KL, et al. The distribution and mechanism of action of ghrelin in the CNS demonstrates a novel hypothalamic circuit regulating energy homeostasis. Neuron. 2003 Feb;37(4):649-61.

14 Lu S, Guan JL, Wang QP, Uehara K, Yamada $\mathrm{S}$, Goto N, et al. Immunocytochemical observation of ghrelin-containing neurons in the rat arcuate nucleus. Neurosci Lett. 2002 Mar; 321(3):157-60.

15 Menyhért J, Wittmann G, Hrabovszky E, Szlávik N, Keller E, Tschöp M, et al. Distribution of ghrelin-immunoreactive neuronal networks in the human hypothalamus. Brain Res. 2006 Dec;1125(1):31-6.

16 Mondal MS, Date Y, Yamaguchi H, Toshinai K, Tsuruta T, Kangawa K, et al. Identification of ghrelin and its receptor in neurons of the rat arcuate nucleus. Regul Pept. 2005 Mar; 126(1-2):55-9.

17 Edwards A, Abizaid A. Clarifying the Ghrelin System's Ability to Regulate Feeding Behaviours despite Enigmatic Spatial Separation of the GHSR and Its Endogenous Ligand. Int Mol Sci. 2017 Apr;18(4):E859.

18 Kageyama H, Kitamura Y, Hosono T, Kintaka Y, Seki M, Takenoya F, et al. Visualization of ghrelin-producing neurons in the hypothalamic arcuate nucleus using ghrelin-EGFP transgenic mice. Regul Pept. 2008 Jan;145(13):116-21.
19 Ali EF, Cayer C, Wellman M, Abizaid A, James JS, Merali Z. In vivo ghrelin release from the arcuate nucleus measured by pushpull perfusion. Proc Soc Neurosci, 44th Annual Meeting, Washington, DC, USA, November 15-19, 2014.

20 Guan JL, Wang QP, Kageyama H, Takenoya F, Kita T, Matsuoka T, et al. Synaptic interactions between ghrelin- and neuropeptide $\mathrm{Y}$ containing neurons in the rat arcuate nucleus. Peptides. 2003 Dec;24(12):1921-8.

21 Guan JL, Okuda H, Takenoya F, Kintaka Y, Yagi M, Wang L, et al. Synaptic relationships between proopiomelanocortin- and ghrelincontaining neurons in the rat arcuate nucleus. Regul Pept. 2008 Jan;145(1-3):128-32.

22 Toshinai K, Date Y, Murakami N, Shimada M, Mondal MS, Shimbara T, et al. Ghrelininduced food intake is mediated via the orexin pathway. Endocrinology. 2003 Apr;144(4): 1506-12.

23 Dalvi PS, Nazarians-Armavil A, Purser MJ, Belsham DD. Glucagon-like peptide-1 receptor agonist, exendin-4, regulates feeding-associated neuropeptides in hypothalamic neurons in vivo and in vitro. Endocrinology. 2012 May; 153(5):2208-22.

24 Hong X, Zhang H, Liang H, Li D, Huang J, Li $Z$, et al. Exendin-4 decreases ghrelin levels through mTOR signaling. Mol Cell Endocrinol. 2016 Dec;437:201-12.

25 Lu K, Chen X, Yan J, Li X, Huang C, Wan Q, et al. The Effect of Feeding Behavior on Hypothalamus in Obese Type 2 Diabetic Rats with Glucagon-Like Peptide-1 Receptor Agonist Intervention. Obes Facts. 2018;11(3): 181-94.

26 Watson C, Paxinos G. The rat brain in stereotaxic coordinates. Volume 1. 7th ed. China: PMPH; 2014. pp. 100-5.

27 Begg DP, Mul JD, Liu M, Reedy BM, D’Alessio DA, Seeley RJ, et al. Reversal of diet-induced obesity increases insulin transport into cerebrospinal fluid and restores sensitivity to the anorexic action of central insulin in male rats. Endocrinology. 2013 Mar;154(3):1047-54.
28 Jessen L, Smith EP, Ulrich-Lai Y, Herman JP, Seeley RJ, Sandoval D, et al. Central Nervous System GLP-1 Receptors Regulate Islet Hormone Secretion and Glucose Homeostasis in Male Rats. Endocrinology. 2017 Jul;158(7): 2124-33.

29 Aoki K, Kamiyama H, Masuda K, Kamiko K, Noguchi Y, Tajima K, et al. Effects of miglitol, vildagliptin, or their combination on serum insulin and peptide YY levels and plasma glucose, cholecystokinin, ghrelin, and obestatin levels. Endocr J. 2014;61(3):249-56.

30 Kastin AJ, Akerstrom V. Entry of exendin-4 into brain is rapid but may be limited at high doses. Int J Obes Relat Metab Disord. 2003 Mar;27(3):313-8.

31 Russo C, Russo A, Pellitteri R, Stanzani S. Ghrelin-containing neurons in the olfactory bulb send collateralized projections into medial amygdaloid and arcuate hypothalamic nuclei: neuroanatomical study. Exp Brain Res. 2018 Aug;236(8):2223-9.

32 Yanagi S, Sato T, Kangawa K, Nakazato M. The Homeostatic Force of Ghrelin. Cell Metab. 2018 Apr;27(4):786-804.

33 Hosoda H, Kangawa K. The autonomic nervous system regulates gastric ghrelin secretion in rats. Regul Pept. 2008 Feb;146(1-3): $12-8$.

34 Ibrahim Abdalla MM. Ghrelin - Physiological Functions and Regulation. Eur Endocrinol. 2015 Aug;11(2):90-5.

35 Patterson M, Murphy KG, Patel SR, Patel NA, Greenwood HC, Cooke JH, et al. Hypothalamic injection of oxyntomodulin suppresses circulating ghrelin-like immunoreactivity. Endocrinology. 2009 Aug;150(8):3513-20.

36 Baker CA, Ma L, Casareale CR, Carlson BA. Behavioral and Single-Neuron Sensitivity to Millisecond Variations in Temporally Patterned Communication Signals. J Neurosci. 2016 Aug;36(34):8985-9000.

37 Jones I, Yelhekar TD, Wiberg R, Kingham PJ, Johansson S, Wiberg M, et al. Development and validation of an in vitro model system to study peripheral sensory neuron development and injury. Sci Rep. 2018 Oct;8(1): 15961. 